\title{
Posição do racemo e do fruto na qualidade fisiológica de sementes de mamona durante $o$ armazenamento ${ }^{1}$
}

\author{
Quality of castor bean seeds (Ricinus communis 1.) affected by \\ raceme and fruit position during storage
}

\author{
Carla Gomes Machado ${ }^{2 *}$; Cibele Chalita Martins 3 ; Simério Carlos Silva Cruz; \\ João Nakagawa ${ }^{4}$; Francisco Rafael da Silva Pereira ${ }^{2}$
}

\begin{abstract}
Resumo
O trabalho teve por objetivo determinar a influência da posição do racemo na planta, do fruto no racemo e do armazenamento na qualidade fisiológica de sementes de mamona (Ricinus communis L.) da cultivar AL Guarany 2002. Os tratamentos foram: posição do racemo na planta (primário, secundário e terciário) e posição dos frutos no racemo (inferior, médio e superior). Depois da extração dos frutos, as sementes foram armazenadas em condições ambientais para avaliações trimestrais de qualidade fisiológica até os doze meses. O delineamento experimental utilizado foi o inteiramente casualizado com parcelas subdivididas. Na parcela foi estudado o fatorial e nas subparcelas os tempos de armazenamento. Foram determinados no momento da colheita e aos três, seis, nove e doze meses o grau de umidade das sementes, a germinação e o vigor (primeira contagem do teste de germinação, envelhecimento acelerado, crescimento e massa de matéria seca de plântulas). A posição do racemo e dos frutos no racemo em mamoneira não influencia a porcentagem de germinação de sementes de mamoneira. Com o decorrer do armazenamento a dormência das sementes diminui e aumenta a porcentagem de plântulas anormais, a massa de matéria seca, o comprimento total, de raiz e de hipocótilo das plântulas.
\end{abstract}

Palavras-chave: Ricinus communis L, posição da infrutescência, conservação, deterioração, oleaginosa

\begin{abstract}
The present research had as objective to evaluate the influence of raceme and fruit position on physiological quality of castor bean seeds (Ricinus communis L.) during storage of cultivar AL Guarany 2002. The treatments were: position of the raceme in plants (primary, secondary and tertiary) and position of fruit in racemes (low, medium and high). After fruit extraction, seeds were stored under environmental conditions for twelve months. The experimental design used was the completely randomized in a split-plot arrangement. Main plots consisted of the interaction raceme $\mathrm{x}$ fruit position and subplots were the storage time. Physiological quality was evaluated quarterly through tests of moisture content, germination and vigor (first count, accelerated aging, seedling length and seedling dry matter). Neither the position of racemes in the plant nor fruit in racemes does not affect germination of castor bean seeds. Dormancy of castor bean seeds decreases during storage, but also increases percentage of abnormal seedlings, seedling dry matter and root, hypocotyl and seedling total length.
\end{abstract}

Key words: Ricinus communis L, fruit position, conservation, deterioration, oil crop

1 Parte da Dissertação de Mestrado da primeira autora apresentada a FCA/UNESP- Universidade Estadual de São Paulo, Botucatu - SP.

2 Eng. Agr ${ }^{\circ}$, Doutorandos do Departamento de Produção Vegetal, FCA/UNESP. E-mail: carlagm@fca.unesp.br; simerio@fca. unesp.br; pereirafrs@fca.unesp.br

3 Eng. Agr ${ }^{\circ}$., Dr ${ }^{\mathrm{a}}$., Professora, Departamento de Produção Vegetal, FCA/UNESP, Rua José Barbosa de Barros, 1780, Caixa Postal 237, Fazenda Experimental Lageado, CEP 18610-307, Botucatu, SP. E-mail: cibele@fca.unesp.br

${ }^{4}$ Eng. Agr ${ }^{\circ}$, Dro ${ }^{\circ}$, Professor Titular Aposentado, Departamento de Produção Vegetal, FCA/UNESP, Rua José Barbosa de Barros, 1780, Caixa Postal 237, Fazenda Experimental Lageado, CEP 18610-307, Botucatu, SP. E-mail: secdamv@fca.unesp.br

* Autor para correspondência

Recebido para publicação 10/06/08 Aprovado em 02/03/10 


\section{Introdução}

Plantas de mamona apresentam florescimento e fertilização prolongados, pois esses eventos ocorrem junto com o desenvolvimento da planta, que apresenta hábito de crescimento indeterminado. Cada racemo, fruto ou semente de uma mesma planta pode ser formado em condições edafoclimáticas diferentes. Portanto, sementes colhidas em diferentes racemos ou posições no racemo são afetadas pelas condições ambientais vigentes antes e durante a sua formação podendo apresentar germinação e vigor distintos; essas características podem influenciar a qualidade inicial das sementes e o seu potencial de armazenamento (LUCENA et al., 2006).

A posição do fruto na planta, do fruto na infrutescência ou da semente no fruto também pode afetar a ocorrência de dormência. Lago et al. (1979) constataram em sementes de mamona diferentes porcentagens de dormência dependendo dos racemos e das variedades cultivadas; essas diferenças podem ser atribuídas às diferentes condições edafoclimáticas vigentes, pois sabe-se que a dormência é causada por fatores genéticos e ambientais (CARVALHO; NAKAGAWA, 2000).

O momento da colheita é um dos mais importantes fatores que afetam tanto a qualidade quanto a quantidade das sementes de mamona devido a desuniformidade de maturação. Para minimizar essa desuniformidade e maximizar a qualidade das sementes, a colheita dos racemos de mamoneira de cultivares deiscentes é feita periodicamente em várias vezes tornando-se uma operação dispendiosa, por ser, também, manual (GONÇALVES; BENDEZÚ; LIMA, 1981; CARTAXO et al., 2004). Para cultivares com frutos indeiscentes como a AL Guarany 2002, a colheita dos racemos é realizada numa única operação, resultando num lote com mistura de frutos em diferentes estádios de maturação (SILVA; CARVALHO; SILVA, 2001). Corrêa, Távora e Pitombeira (2006), afirmam que não há vantagem em estender a colheita para além do racemo terciário, pois além de aumentar a porcentagem de sementes chochas, a partir do racemo quaternário a quantidade de sementes produzidas é muito baixa.

O estádio de maturação pode influenciar a qualidade das sementes, pois sementes colhidas antes ou após a maturidade fisiológica apresentam menor qualidade e potencial de armazenamento (CARVALHO; NAKAGAWA, 2000). Assim, o escalonamento de colheita ou estratégias que permitam a seleção de frutos num mesmo racemo, ou de um ou mais dos três primeiros racemos, podem resultar em sementes com estádio de maturação similar e na obtenção de lotes mais uniformes e de melhor qualidade (CARVALHO; NAKAGAWA, 2000; LUCENA et al., 2006).

Após a colheita, as condições climáticas tropicais e subtropicais vigentes no Brasil são desfavoráveis à manutenção da qualidade de sementes ortodoxas, como as de mamoneira, pois, a baixa temperatura e umidade relativa do ar constituem as melhores condições de armazenamento por reduzirem a atividade metabólica do embrião e a deterioração (MARCOS FILHO, 2005).

Em condições ambientais, sem controle de temperatura e umidade relativa do ar, as sementes de mamoneira conseguem manter a germinação em taxas maiores que $80 \%$ por até 21 meses de armazenamento; em alguns casos, o armazenamento por mais de seis meses é favorável à germinação, devido à superação da dormência, como foi constatado por Lago et al. (1979). Os estresses sofridos pela planta mãe durante o desenvolvimento da cultura e a qualidade inicial das sementes também afetam o potencial de conservação (FREITAS, 1999).

Assim, o objetivo do trabalho foi verificar a influência da posição do racemo na planta, do fruto no racemo e do armazenamento na qualidade de sementes de mamona da cultivar Al Guarany 2002. 


\section{Material e Métodos}

O experimento de campo foi conduzido, na área de experimentação da Faculdade de Ciências Agronômicas da UNESP, Campus de Botucatu em solo classificado como Nitossolo Vermelho Estruturado (EMBRAPA, 1999). O experimento foi instalado em uma área uniforme de $1.638 \mathrm{~m}^{2}$ e no preparo foi utilizado o sistema convencional, constando de uma aração e duas gradagens. A semeadura foi realizada no dia 21 de novembro de 2005 com espaçamento entre linhas de 1,8 m e entre plantas na linha de $1,0 \mathrm{~m}$. A adubação foi calculada tomando-se como base os resultados da análise química de solo, cuja amostragem foi feita antes do preparo da área. A cultura recebeu todos os tratos culturais e fitossanitários de acordo com as recomendações para a cultura.

A colheita foi realizada manualmente no dia 25 de abril de 2006, cortando-se os três primeiros racemos maduros de 284 plantas selecionadas ao acaso.
As condições climáticas vigentes desde o início do florescimento das plantas no dia 10 de janeiro, até a colheita dos frutos, estão apresentadas na (Figura 1).

Tratamentos avaliados: Posição do racemo na planta - Os racemos primário (1), secundário (2) e terciário (3) foram colhidos separadamente de acordo com sua posição na planta. Posição do fruto no racemo - Com o auxílio de uma fita métrica, cada tipo de racemo foi dividido em três segmentos de comprimento iguais, denominados terço superior (S), médio (M) e inferior (I).

Após as subdivisões dos racemos, foi feita a extração e limpeza manual das sementes, retirandose as sementes chochas e as impurezas. As sementes foram separadas em subamostras e armazenadas por doze meses em sacos de papel do tipo "Kraft" 90 gramas, fundo quadrado $(72 \times 57 \mathrm{~cm})$, no laboratório, sem controle das condições ambientais.

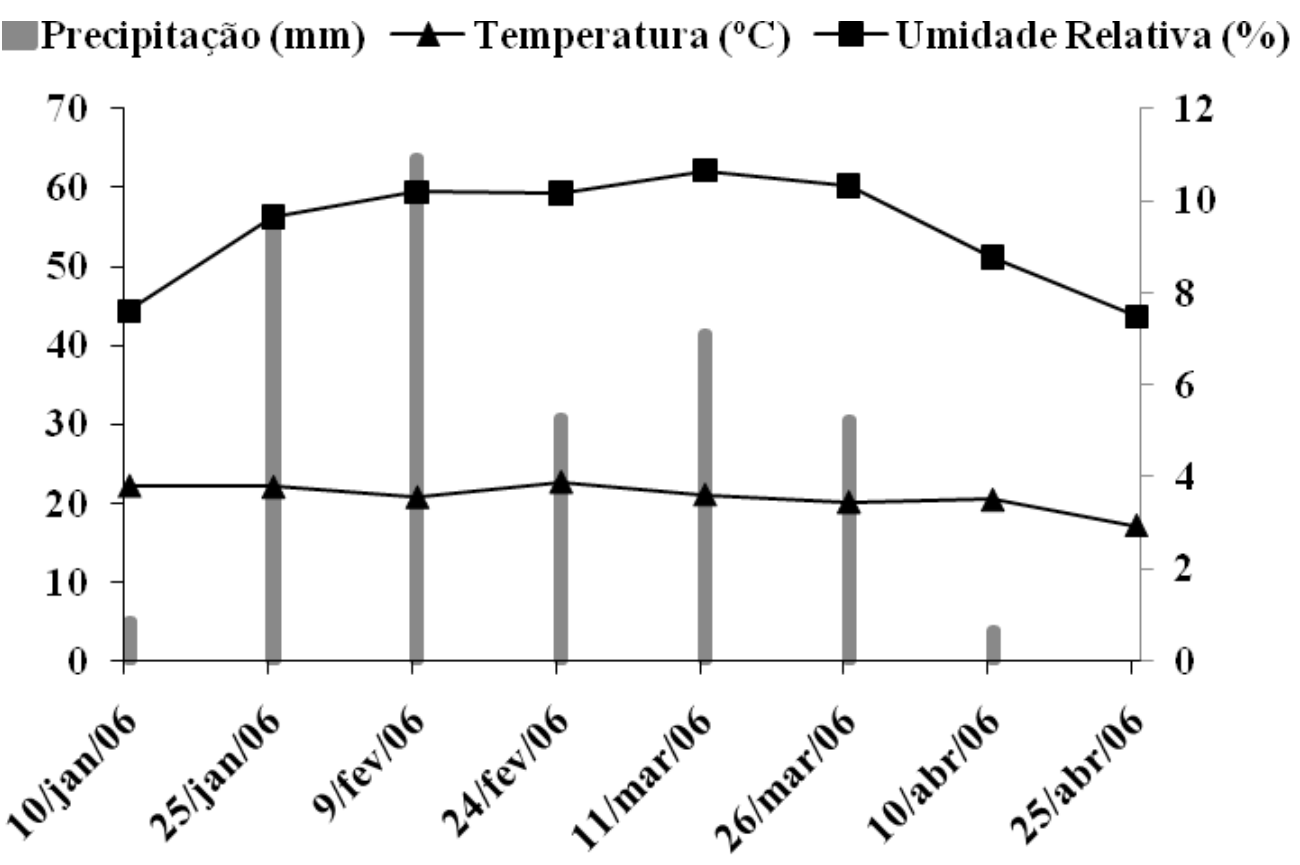

Período entre o florescimento e a colheita

Figura 1. Média quinzenal da temperatura, umidade relativa do ar e precipitação registradas entre o período de florescimento e a colheita dos frutos de mamoneira. Botucatu-SP, 2006. 
Os dados de temperatura e umidade relativa do ambiente duranteo armazenamento foramregistrados por um termohigrógrafo. Inicialmente e, a cada três meses até os 12 meses, a qualidade das sementes foi avaliada pelos seguintes testes e determinações: Grau de umidade- foi determinado pelo método da estufa a $105 \pm 3^{\circ} \mathrm{C}$ por $24 \mathrm{~h}$ com quatro subamostras de cinco sementes por tratamento (BRASIL, 1992). Teste de germinação - foi instalado com oito subamostras de 25 sementes por tratamento, em rolos de papel toalha tipo Germitest, umedecidos com 2,5 vezes a massa (g) do papel em água, dispostos na posição horizontal em germinador mantido com temperaturas alternadas de $20-30^{\circ} \mathrm{C}$ por 16/8 horas respectivamente. Durante o teste, os rolos de papel permaneceram acondicionados dentro de sacos plásticos de $0,033 \mathrm{~mm}$ de espessura fechados, para evitar a desidratação (COIMBRA et al., 2007). A primeira contagem foi realizada aos sete dias após a semeadura e a contagem final aos 14 dias quando foram avaliadas as porcentagens de plântulas normais, anormais, sementes dormentes e mortas (BRASIL,1992); Primeira contagem do teste de germinação - realizada a partir dos dados obtidos na data da primeira contagem do teste de germinação, contabilizando-se a porcentagem de plântulas normais (VIEIRA; CARVALHO, 1994); Envelhecimento acelerado - foram colocadas sementes para envelhecer em camada única sobre tela em caixas plásticas transparentes $(11 \times 11 \times 3,5$ $\mathrm{cm})$, contendo $40 \mathrm{~mL}$ de água, mantidas a $42^{\circ} \mathrm{C}$ por 24 horas, seguindo-se do teste de germinação em substrato umedecido com duas vezes a massa do papel em água e contagem no sétimo dia, quando foram avaliados as porcentagens de plântulas normais e sementes dormentes. O grau de umidade das sementes foi determinado após o envelhecimento (VIEIRA; CARVALHO, 1994; SOUZA; CAVARIANI; NAKAGAWA, 2007); Crescimento de plântulas - foram utilizadas 4 subamostras de 10 sementes por tratamento, semeadas em rolo de papel, mantidos à $25^{\circ} \mathrm{C}$ (VIEIRA; CARVALHO, 1994). Aos 9 dias após a semeadura, foi mensurado com régua $(\mathrm{cm})$ o comprimento da raiz, do hipocótilo e total das plântulas normais e considerado o número total de sementes instaladas para o cálculo da média de cada repetição (VANZOLINI, et al., 2007); Massa de matéria seca de plântulas - As plântulas normais obtidas no teste de crescimento de plântulas tiveram os tecidos de reserva removidos com bisturi e foram colocadas em sacos de papel para secar em estufa a $80^{\circ} \mathrm{C}$ por $24 \mathrm{~h}$. Após esse período, as subamostras foram pesadas para o cálculo da massa da matéria seca por plântula (mg/plântula) (VIEIRA; CARVALHO, 1994).

O delineamento experimental foi o inteiramente casualizado com parcelas subdivididas no tempo, com quatro subamostras. Foram estudados durante cinco tempos de armazenamento (zero, três, seis, nove e 12 meses) os tratamentos constituídos pelo fatorial $3 \times 3$, sendo três posições dos racemos nas plantas e três posições dos frutos no racemo. Na parcela foi estudado o fatorial, e nas subparcelas os tempos de armazenamento. Os dados foram submetidos à análise de variância e os tratamentos foram comparados por meio de análise de regressão em função do tempo de armazenamento quando houve efeito significativo a 1 e $5 \%$ de probabilidade. Foram ajustadas equações de regressão até segundo grau, escolhendo-se as significativas com maior coeficiente de determinação $\left(\mathrm{R}^{2}\right)$.

\section{Resultados e Discussão}

As sementes dos diferentes racemos e posições nos racemos apresentaram graus de umidade iniciais relativamente baixos e uniformes, entre 5,6 e 6,0\%. Esses valores são justificados pela colheita após a maturidade fisiológica das sementes e pela ausência de chuvas e baixa umidade relativa do ar (44\%) na época da colheita (Figura 1). Por esses resultados, pode-se inferir que o teor de água não deve ter alterado o comportamento fisiológico das sementes de diferentes posições do racemo na planta e do fruto no racemo durante o armazenamento; pois 
considerando-se que o teor de água inicial é um fator primordial para a padronização das avaliações a serem realizadas posteriormente, esses resultados asseguram a credibilidade dos dados obtidos no trabalho (COIMBRA et a., 2009). Durante o armazenamento, os teores de água na semente apresentaram pouca variação (Tabela 1). Nestes 12 meses de armazenamento, as médias da umidade relativa e da temperatura foram respectivamente de $45 \%$ e $26^{\circ} \mathrm{C}$.

Tabela 1. Médias do grau de umidade (\%) de sementes oriundas de diferentes posições do racemo na planta e do fruto no racemo durante 12 meses de armazenamento, com as respectivas variações.

\begin{tabular}{cccc}
\hline \multirow{2}{*}{$\begin{array}{c}\text { Posição do } \\
\text { racemo na }\end{array}$} & \multicolumn{3}{c}{ Posição do fruto no racemo } \\
\cline { 2 - 4 } Planta & Inferior & Médio & Superior \\
\hline Primário & $5,3 \pm 0,2$ & $5,3 \pm 0,4$ & $5,4 \pm 0,4$ \\
Secundário & $5,2 \pm 0,3$ & $5,3 \pm 0,3$ & $5,6 \pm 0,7$ \\
Terciário & $5,3 \pm 0,4$ & $5,3 \pm 0,3$ & $5,2 \pm 0,3$ \\
\hline
\end{tabular}

A análise de variância dos dados da germinação (plântulas normais, anormais, sementes mortas e dormentes) e de envelhecimento acelerado (plântulas normais e sementes dormentes), apresentou efeito significativo apenas para o tempo de armazenamento, indicando assim que o comportamento durante o armazenamento foi semelhante para as sementes de todas as posições dos racemos e nos racemos. Diante disto, a análise da regressão polinomial foi realizada para estas variáveis em função do tempo de armazenamento, independentemente da posição do racemo na planta e do fruto no racemo, estando as curvas ajustadas e as equações das regressões com os respectivos valores de $\mathrm{R}^{2}$ apresentados nas (Figuras 2 e 3), para dados do teste de germinação e de envelhecimento acelerado, respectivamente.

Esses resultados discordam dos apresentados por Lins, Távora e Alves (1976) para a cultivar Paraibana, mas concordam com os obtidos para a cultivar Sipeal 1, a qual não apresentou diferença de germinação das sementes entre os três primeiros racemos.

As sementes ao serem armazenadas apresentavam germinação $1 \mathrm{I}=88 \%, 1 \mathrm{M}=88 \%$ e $1 \mathrm{~S}=92 \%, 2 \mathrm{I}=$ $87 \%, 2 \mathrm{M}=90 \%$ e $2 \mathrm{~S}=86 \%, 3 \mathrm{I}=85 \%, 3 \mathrm{M}=87 \%$ e $3 \mathrm{~S}=90 \%$; correspondendo a uma média de $87 \%$. As altas porcentagens de germinação no início do armazenamento se devem, entre outros, às condições ambientais favoráveis, baixas temperaturas, em torno de $21^{\circ} \mathrm{C}$ e baixa umidade relativa, em torno de $55 \%$ a partir da maturação dos racemos (Figura 1). Assim, como observado na Figura 2, a porcentagem de germinação se ajustou a uma equação de $2^{\circ}$ grau, observando-se que no início do armazenamento a porcentagem de germinação estava dentro dos padrões de comercialização, acima de $85 \%$ (PINTO, 2005), porém, no decorrer do tempo de armazenamento, aos três, seis e nove meses ela foi reduzida situando-se em torno de $82 \%$ voltando a aumentar aos doze meses para $87 \%$, retomando os padrões de comercialização da espécie. 


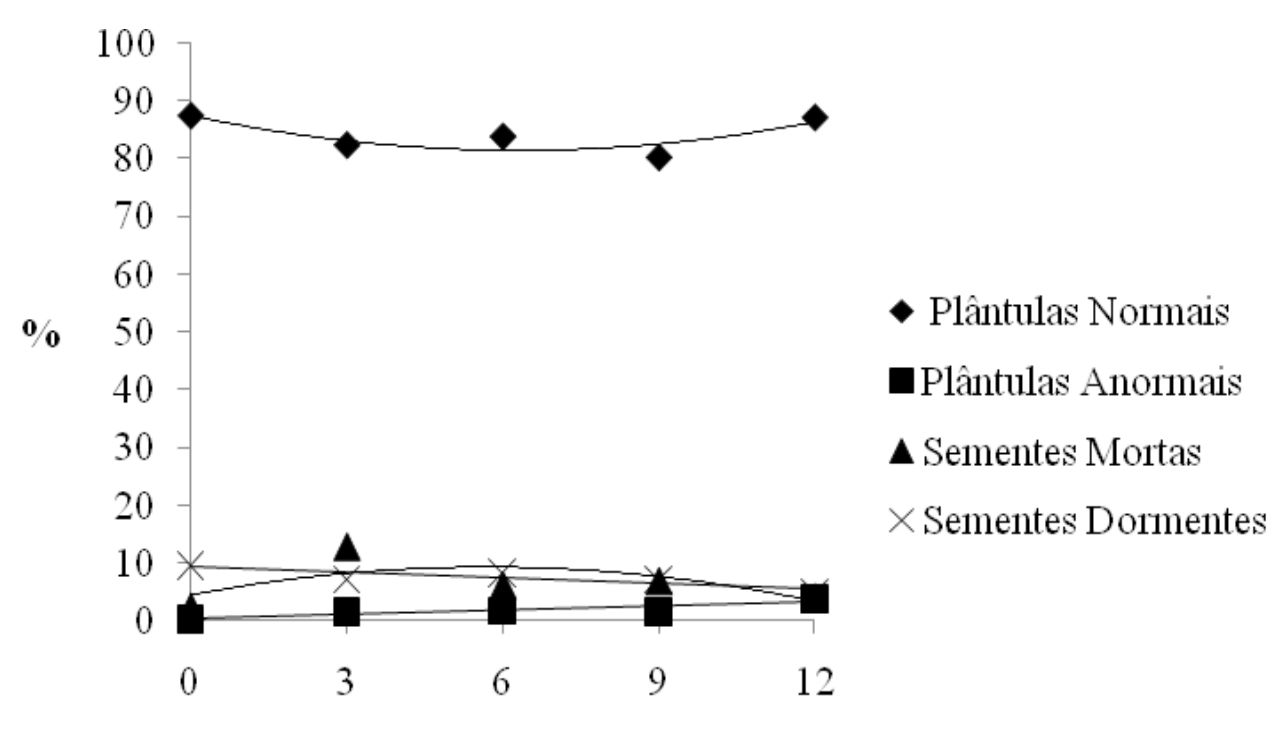

\section{Tempo de armazenamento (meses)}

Figura 2. Plântulas normais ( $\left.Y=0,1521 x^{2}-1,9198 x+87,449 ; R^{2}=0,68\right)$, anormais $\left(Y=0,2352 x+0,4 ; R^{2}=0,79\right)$, sementes mortas $\left(Y=-0,1495 x^{2}+1,7029 x+4,4651 ; R^{2}=0,42\right)$ e dormentes $\left(Y=-0,3167 x+9,3333 ; R^{2}=0,74\right)$ referentes ao teste de germinação (\%) de sementes de mamona armazenadas em ambiente natural de laboratório durante 12 meses.

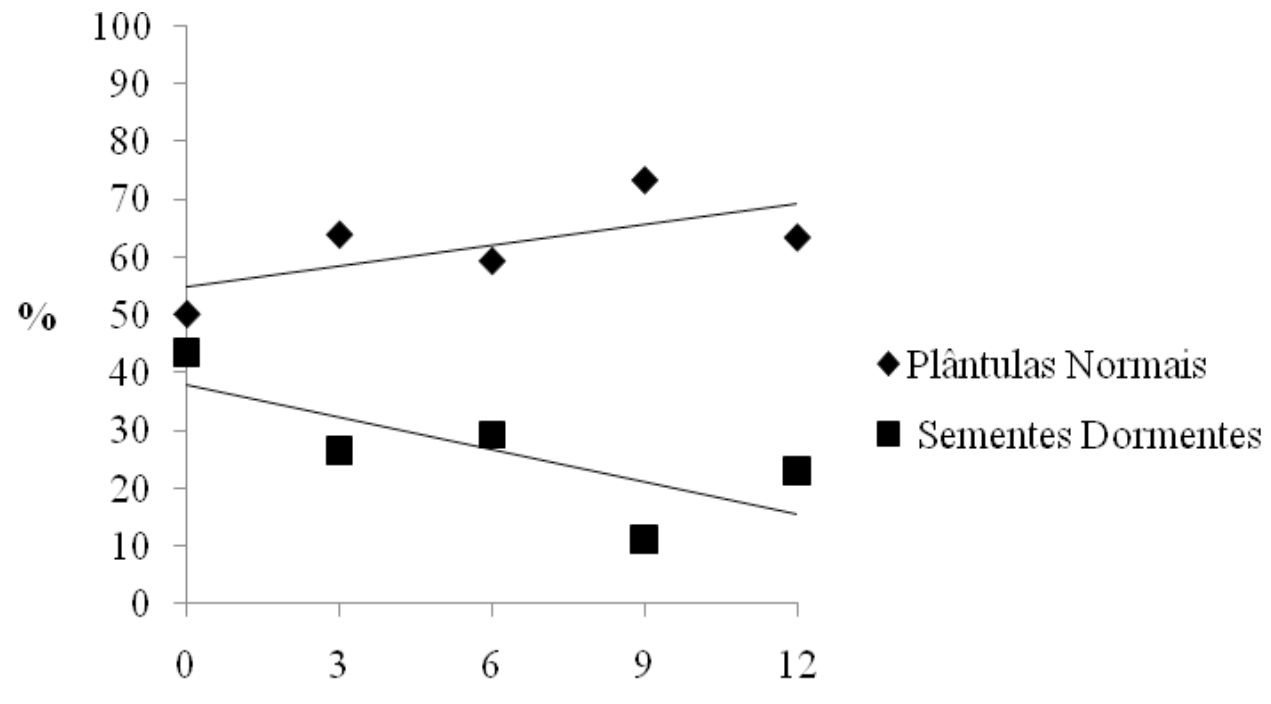

Tempo de armazenamento (meses)

Figura 3. Plântulas normais $(Y=1,1944 x+54,9 ; R 2=0,46)$ e sementes dormentes $(Y=-1,8722 x+37,933$; $2=0,58)$ referentes ao teste de envelhecimento acelerado (\%) de sementes de mamona armazenadas em ambiente natural laboratório durante 12 meses.

Os dados referentes a dormência das sementes (Figura 2), se ajustaram a equação linear. Assim pode-se notar que com o decorrer do armazenamento a dormência das sementes diminuiu. Lago et al. (1979), verificaram para várias cultivares de mamona que houve redução da dormência das sementes ao longo do armazenamento, sendo esta praticamente nula a partir dos nove meses de armazenamento, porém as cultivares estudadas e o método de colheita diferiram do presente trabalho, 
pois a colheita dos três primeiros racemos foi feita parceladamente à medida que estes foram atingindo a maturação.

Pelos dados de sementes mortas pode-se notar um comportamento oposto e coerente com os dados referentes a plântulas normais; ajustando-se também a uma equação quadrática (Figura 2). Notase que no início do armazenamento a porcentagem de sementes mortas estava baixa, em torno de $3 \%$ porém, no decorrer do tempo de armazenamento, aos três, seis e nove meses ela aumentou um pouco ficando em torno de $9 \%$, voltando a diminuir aos doze meses de armazenamento.

A ocorrência de plântulas anormais aumentou lineamente com o decorrer do tempo de armazenamento (Figura 2). Este resultado é explicável pelo processo de deterioração, pois o aumento do número de plântulas anormais é uma das características do processo (DELOUCHE, 1963).

As sementes de diferentes racemos na planta e frutos no racemo armazenadas por zero, três, seis, nove e doze meses apresentaram graus de umidade após o envelhecimento de, respectivamente, 12,8 \pm $0,4 \% ; 12,6 \pm 0,5 \% ; 12,9 \pm 0,3 \% 14,1 \pm 1,7$ e 13,3 $\pm 1,0$. Assim, pode-se afirmar que as diferenças de umidade entre os tratamentos e amostras avaliadas foram inferiores a $2 \%$ e não comprometeram a credibilidade dos resultados dos testes de envelhecimento acelerado (MARCOS FILHO, 1999). Pelas curvas ajustadas, o vigor apresentado pelo teste do envelhecimento acelerado (Figura 3) mostrou que este aumentou, podendo ser atribuído a embebição, provocada pela alta temperatura e umidade relativa, pois estas condições podem funcionar como um tratamento para superar a dormência das sementes (VIEIRA, et al. 2002); pois observa-se que as sementes submetidas ao teste de envelhecimento acelerado diminuíram a dormência ao longo do período de armazenamento. Assim, a condição de alta temperatura e alta umidade relativa pode funcionar como tratamento para superação de dormência em sementes de mamona.
A manutenção ou redução da germinação e do vigor das sementes armazenadas em condições não controladas estão relacionadas à temperatura e umidade relativa do ar do ambiente, pois altas umidades relativas e temperaturas aceleram o processo de deterioração de sementes ortodoxas como a mamona (MARCOS FILHO, 2005). Portanto, no armazenamento de sementes, em regiões tropicais e sub-tropicais, os riscos são maiores (SANTOS, 1994). No presente trabalho a umidade relativa durante o armazenamento foi baixa, de $45 \%$ em média, embora as temperaturas tenham sido relativamente altas, de $26^{\circ} \mathrm{C}$ em média. Segundo Harrington (1972), dos dois fatores acima mencionados, a umidade relativa do ar é a mais importante e, desde que a umidade relativa do ambiente de armazenamento seja inferior a $65 \%$, as sementes mantêm a viabilidade sob qualquer condição de temperatura.

A análise de variância dos dados da primeira contagem do teste de germinação, comprimento total de plântulas e comprimento de raiz, apresentou efeito de interação entre todos os tratamentos avaliados (posição do racemo na planta, do fruto no racemo e armazenamento). Face a esses resultados, realizou-se a análise da regressão polinomial dos dados para cada posição do racemo na planta e do fruto no racemo no decorrer dos 12 meses de armazenamento. As equações das regressões e os valores do coeficiente de determinação $\left(\mathrm{R}^{2}\right)$ estão apresentados na (Tabela 2). Nas Figuras 4, 5 e 6 estão representadas, respectivamente, as curvas ajustadas para os dados de primeira contagem do teste de germinação, comprimento total de plântulas e comprimento de raiz, de sementes de mamona armazenadas em condição ambiental de laboratório durante 12 meses.

De acordo com as curvas ajustadas (Figura 4), para todas as posições do racemo na planta e do fruto no racemo, de maneira geral, houve redução nos valores de primeira contagem de germinação até os seis meses de armazenamento. A partir daí aumentou-se a velocidade de germinação pelos 
dados obtidos no teste de primeira contagem. Pode-se inferir que o comportamento dos dados observados na primeira contagem de germinação relaciona-se aos dados de plântulas normais e sementes mortas (Figura 2).

Observa-se pelas curvas ajustadas dos dados de comprimento de plântulas e de raiz (Tabela 2) que para todos os racemos e posições no racemo estas se ajustaram a uma regressão linear, podendo afirmar assim que o comprimento total das plântulas e das raízes de mamona aumentou ao longo dos 12 meses de armazenamento (Figura 5 e 6).
O comprimento do hipocótilo acusou efeito de interação apenas entre posição do racemo na planta e armazenamento; realizando-se análise da regressão polinomial dos dados para cada posição do racemo na planta no decorrer dos 12 meses de armazenamento, estando as curvas ajustadas para os dados, às equações das regressões e os valores de $\mathrm{R}^{2}$ apresentados na na Figura 7. O teste de comprimento do hipocótilo seguiu a mesma tendência dos outros testes de comprimento aumentando ao longo dos 12 meses de armazenamento.

Tabela 2. Equações de regressão polinomial para os dados de primeira contagem do teste de germinação, comprimento total de plântulas e comprimento de raiz originadas de sementes de mamona armazenadas em condição ambiental de laboratório durante 12 meses, com os respectivos coeficientes de determinação $\left(\mathrm{R}^{2}\right)$.

\begin{tabular}{|c|c|c|c|c|}
\hline & Tratamentos & & Equações & $\mathbf{R}^{2}$ \\
\hline \multirow{9}{*}{$\begin{array}{c}\text { Primeira } \\
\text { Contagem da } \\
\text { Germinação (\%) }\end{array}$} & \multirow{3}{*}{ Primário } & Inferior & $Y=0,623 x^{2}-7,5929 x+67,114$ & 0,96 \\
\hline & & Médio & $Y=0,3056 x^{2}-3,45 x+66$ & 0,81 \\
\hline & & Superior & $Y=0,8571 x^{2}-9,5524 x+75,629$ & 0,90 \\
\hline & \multirow{3}{*}{ Secundário } & Inferior & $Y=0,6429 x^{2}-6,881 x+62,371$ & 0,85 \\
\hline & & Médio & $Y=0,3492 x^{2}-5,3571 x+76,686$ & 0,89 \\
\hline & & Superior & $Y=0,2817 x^{2}-4,1976 x+67,271$ & 0,62 \\
\hline & \multirow{3}{*}{ Terciário } & Inferior & $Y=0,3651 x^{2}-4,8476 x+58,171$ & 0,65 \\
\hline & & Médio & $Y=0,8929 x^{2}-10,531 x+70,471$ & 0,95 \\
\hline & & Superior & $Y=0,7778 x^{2}-10,967 x+78,3$ & 0,73 \\
\hline \multirow{9}{*}{$\begin{array}{l}\text { Comprimento } \\
\text { Total de } \\
\text { Plântulas }(\mathrm{cm})\end{array}$} & \multirow{3}{*}{ Primário } & Inferior & $\mathrm{Y}=0,7218 \mathrm{x}+5,8865$ & 0,90 \\
\hline & & Médio & $Y=0,6903 x+8,893$ & 0,87 \\
\hline & & Superior & $Y=1,1686 x+6,3228$ & 0,89 \\
\hline & \multirow{3}{*}{ Secundário } & Inferior & $Y=0,9783 x+6,7055$ & 0,70 \\
\hline & & Médio & $Y=1,0698 x+6,8208$ & 0,72 \\
\hline & & Superior & $Y=1,4131 x+5,4661$ & 0,78 \\
\hline & \multirow{3}{*}{ Terciário } & Inferior & $Y=1,1993 x+5,0395$ & 0,84 \\
\hline & & Médio & $Y=1,2488 x+4,0393$ & 0,91 \\
\hline & & Superior & $Y=0,9867 x+6,034$ & 0,88 \\
\hline \multirow{9}{*}{$\begin{array}{l}\text { Comprimento } \\
\text { De Raiz (cm) }\end{array}$} & \multirow{3}{*}{ Primário } & Inferior & $Y=0,4562 x+4,3325$ & 0,85 \\
\hline & & Médio & $Y=0,5974 x+4,2205$ & 0,86 \\
\hline & & Superior & $Y=0,8383 x+3,16$ & 0,97 \\
\hline & \multirow{3}{*}{ Secundário } & Inferior & $Y=0,478 x+5,3965$ & 0,41 \\
\hline & & Médio & $\mathrm{Y}=0,6218 \mathrm{x}+4,7335$ & 0,73 \\
\hline & & Superior & $Y=0,7985 x+4,5085$ & 0,71 \\
\hline & \multirow{3}{*}{ Terciário } & Inferior & $Y=0,6802 x+4,0245$ & 0,84 \\
\hline & & Médio & $Y=0,7578 x+2,366$ & 0,97 \\
\hline & & Superior & $\mathrm{Y}=0,5194 \mathrm{x}+4,7945$ & 0,77 \\
\hline
\end{tabular}



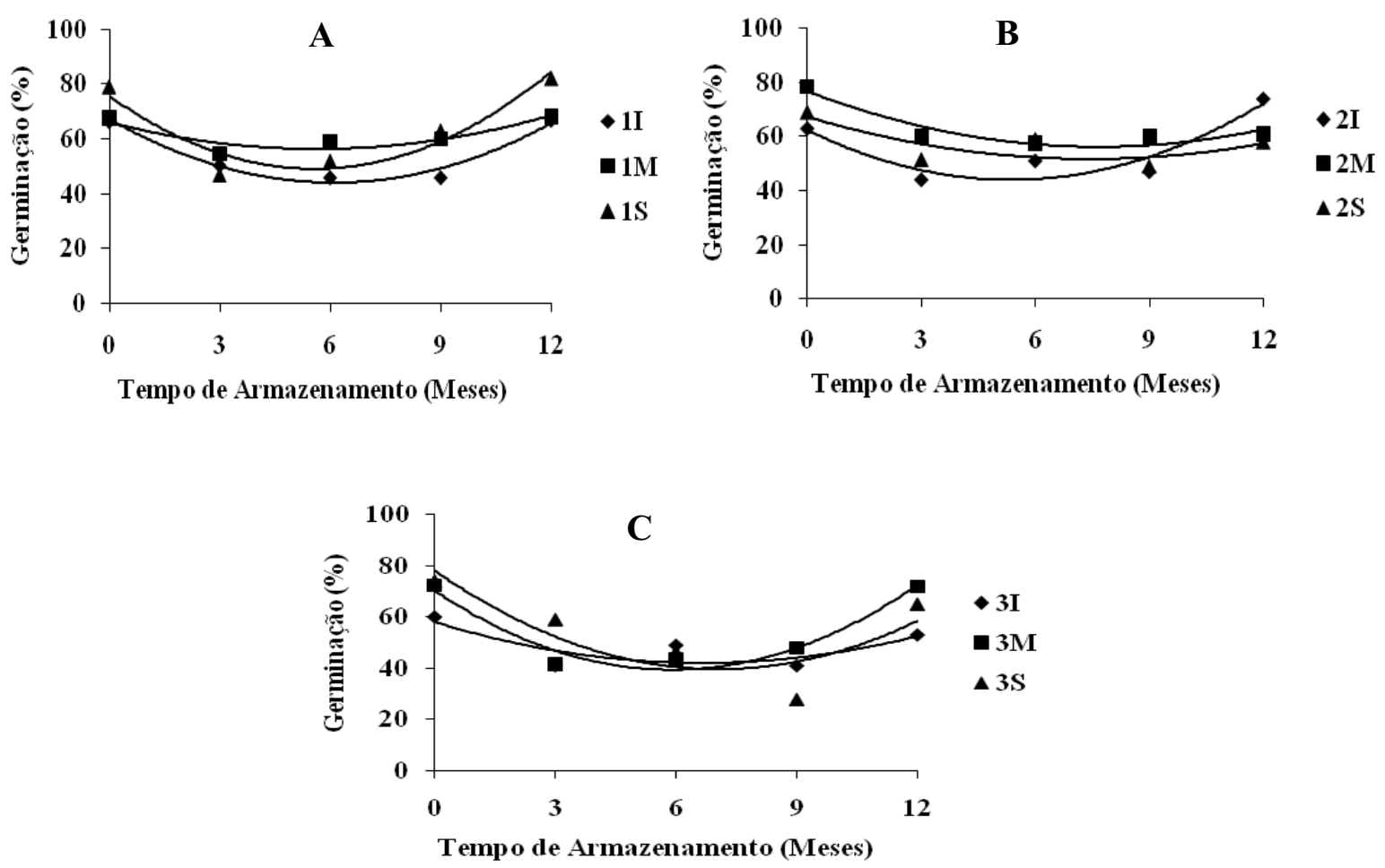

Figura 4. Primeira contagem do teste de germinação de sementes de mamona de diferentes posições do racemo primário $(\mathrm{A})$, secundário $(\mathrm{B})$ e terciário $(\mathrm{C})$ e no racemo $(\mathrm{I}, \mathrm{M}, \mathrm{S})$ em função do armazenamento.

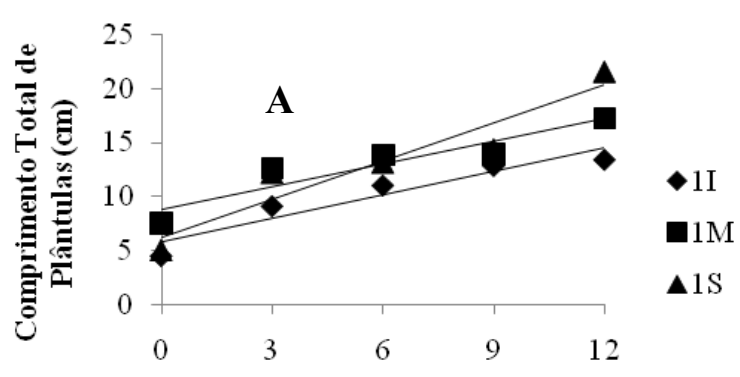

Tempo de armazenamento (meses)

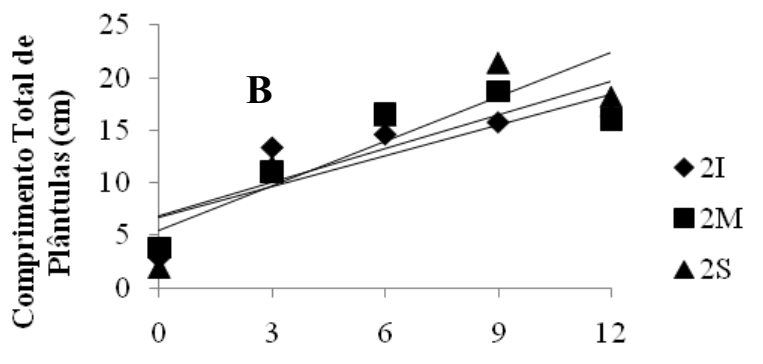

Tempo de armazenamento (meses)

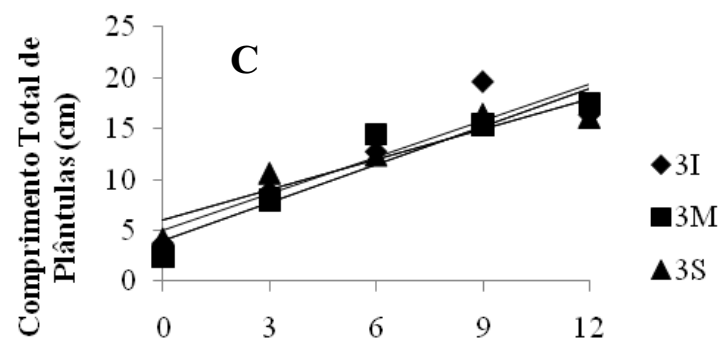

Tempo de armazenamento (meses)

Figura 5. Comprimento total de plântulas $(\mathrm{cm})$ originadas de sementes de mamona de diferentes posições do racemo primário (A), secundário (B) e terciário (C) e no racemo (I, M, S) em função do armazenamento. 


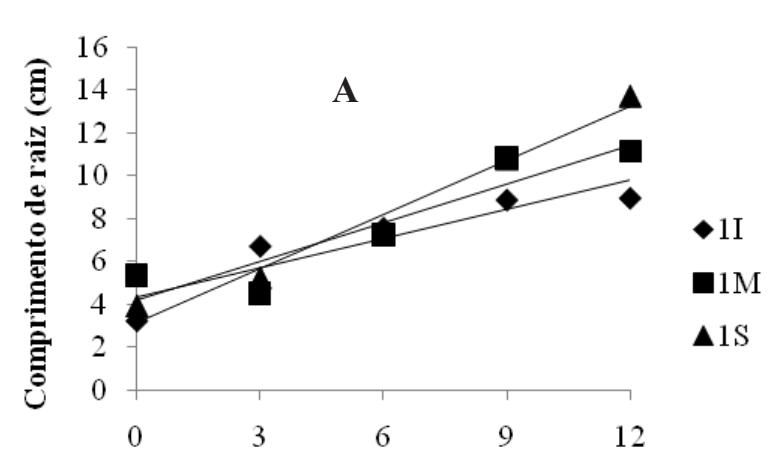

Tempo de armazenamento (meses)

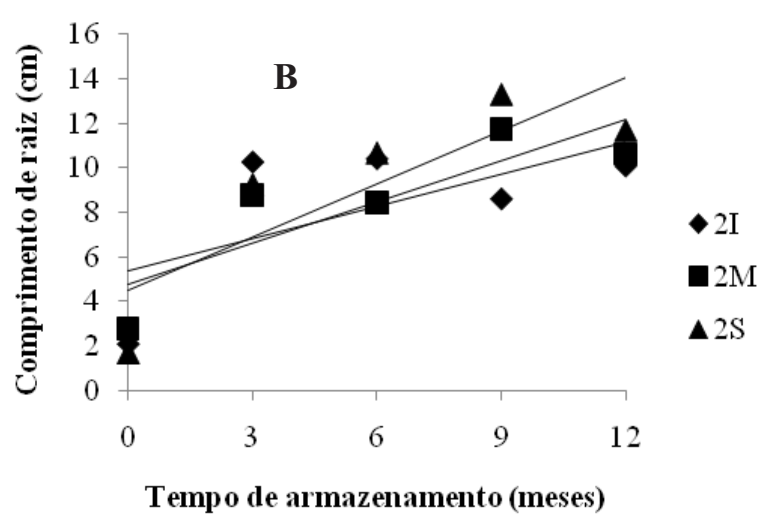

Tempo de armazenamento (meses)

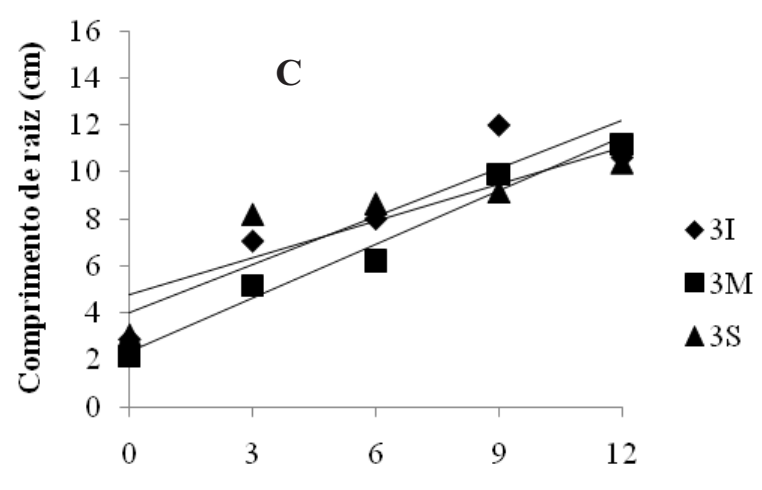

Tempo de armazenamento (meses)

Figura 6. Comprimento da raiz $(\mathrm{cm})$ de sementes de mamona de diferentes posições do racemo primário (A), secundário (B) e terciário (C) e no racemo (I, M, S) em função do armazenamento.

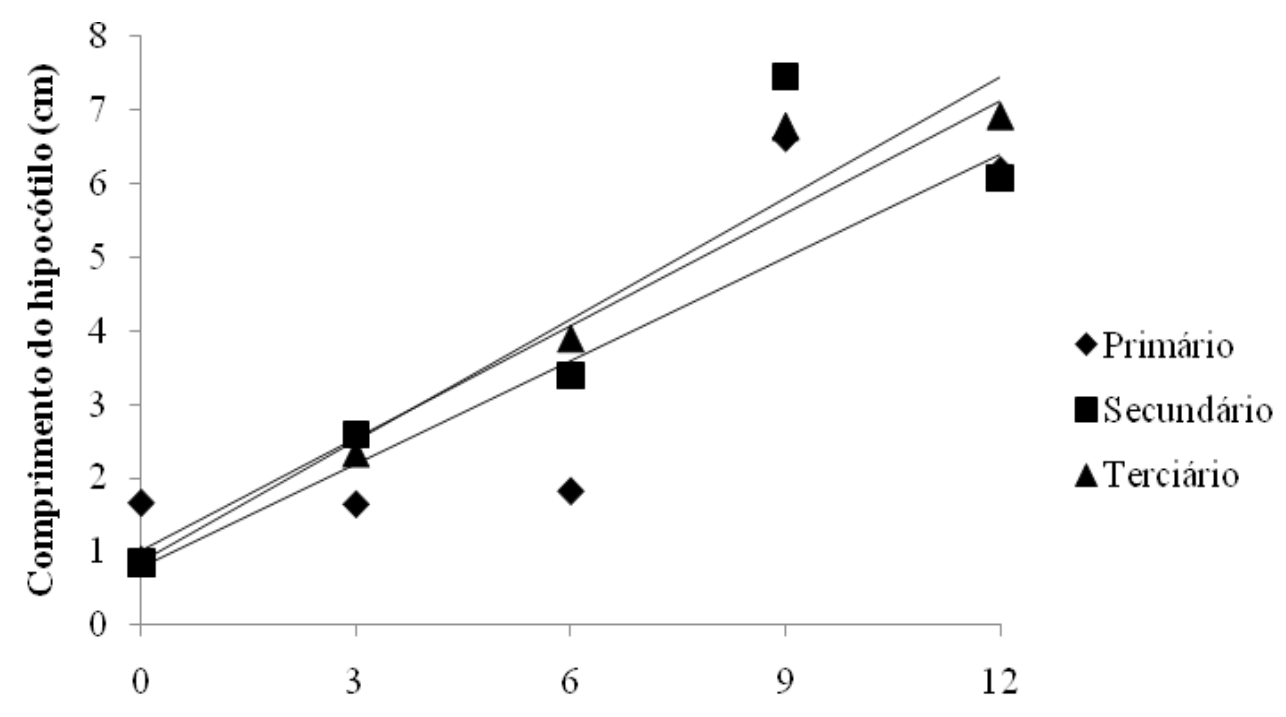

Temp o de armazenamento (meses)

Figura 7. Comprimento do hipocótilo $(\mathrm{cm})$ de sementes de mamona dos racemos primário $(\mathrm{Y}=0,4688 \mathrm{x}+0,776$; $\left.\mathrm{R}^{2}=0,74\right)$, secundário $\left(\mathrm{Y}=0,5107 \mathrm{x}+1,0107 ; \mathrm{R}^{2}=0,82\right)$ e terciário $\left(\mathrm{Y}=0,5495 \mathrm{x}+0,8623 ; \mathrm{R}^{2}=0,95\right)$ em função do armazenamento. 
A análise de variância dos dados de massa de matéria seca de plântulas apresentou efeito significativo apenas do tempo de armazenamento. Diante disto, realizou-se a análise da regressão polinomial para esta variável em função do tempo de armazenamento, independentemente da posição do racemo na planta e do fruto no racemo. A equação de regressão, o valor de $\mathrm{R}^{2}$ e a curva ajustada para os dados de teor de matéria seca estão apresentados na (Figura 8). Este variável aumentou com o decorrer do armazenamento assim como para os testes de comprimento total de plântulas, de raiz e de hipocótilo.

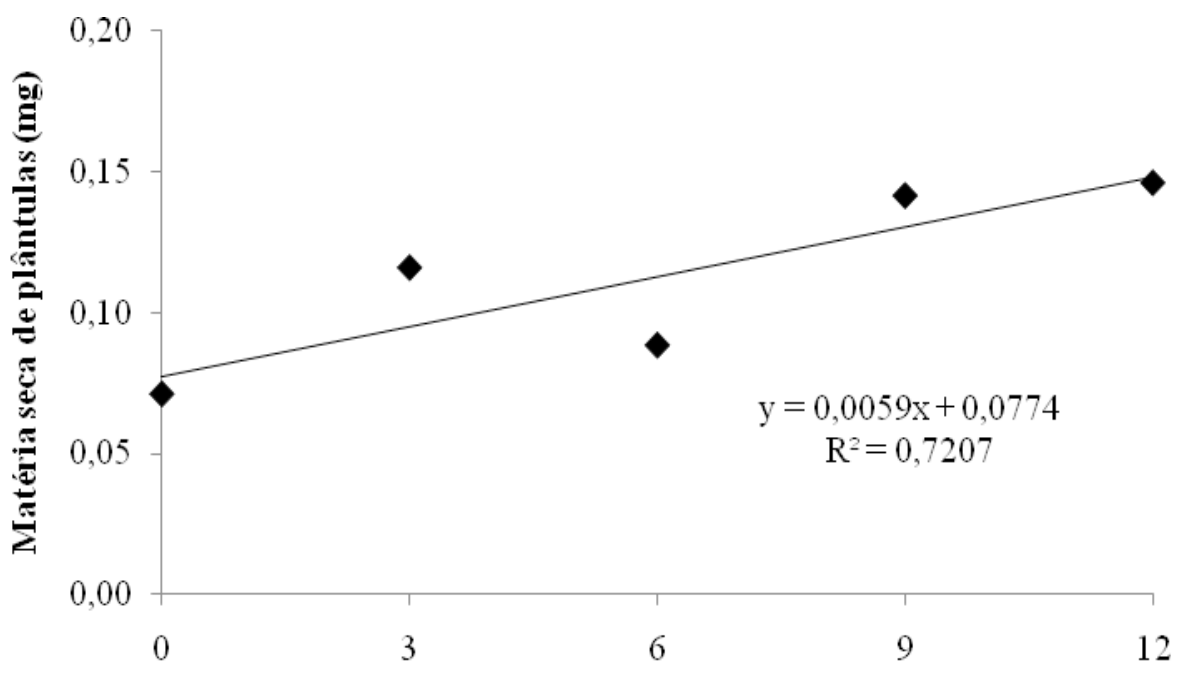

Temp o de armazemento (meses)

Figura 8. Massa de matéria seca de plântulas (mg) provenientes de sementes de mamona armazenadas em condições ambientais de laboratório durante 12 meses.

\section{Conclusões}

A posição do racemo e dos frutos no racemo em mamoneira não influencia a porcentagem de germinação de sementes de mamoneira

Com o decorrer do armazenamento a dormência das sementes diminui e aumenta as plântulas anormais, a matéria seca, o comprimento total, de raiz e de hipocótilo de plântulas.

\section{Agradecimentos}

À CAPES pela concessão de bolsa a primeira autora.

\section{Referências}

BRASIL. Ministério da Agricultura e Reforma Agrária. Secretaria Nacional de Defesa Agropecuária. Departamento Nacional de Defesa Vegetal. Coordenação de Laboratório Vegetal. Regras para análise de sementes. Brasília, $1992.365 \mathrm{p}$.

CARTAXO, W. V.; BELTRÃO, N. E. M.; SILVA, O. R. R. F.; SEVERINO, L. S; SUASSUNA, N. D.;

SOARES, J. J.O Cultivo da mamona no semi-árido brasileiro. Campina Grande: EMBRAPA Algodão, 2004. 20 p. (Circular técnica, 77).

CARVALHO, N. M.; NAKAGAWA, J. Sementes: ciência, tecnologia e produção. 4. ed. Jaboticabal: Funep, 2000. 588 p.

COIMBRA, R. A.; TOMAZ, C. A.; MARTINS, C. C.; NAKAGAWA, J. Teste de germinação com acondicionamento dos rolos de papel em sacos plásticos. Revista Brasileira de Sementes, Pelotas, v. 29, n. 1, p. 92-97, 2007. 
COIMBRA, R. A.; MARTINS, C. C.; TOMAZ, C. A.; NAKAGAWA, J. Testes de vigor utilizados na avaliação da qualidade fisiológica de sementes de milho-doce (sh2). Ciência Rural, Santa Maria, v. 39, n. 9, p. 24022408, 2009.

CORRÊA, M. L. P.; TÁVORA, F. J. A. F.; PITOMBEIRA, J. B. Comportamento de cultivares de mamona em sistemas de cultivo isolados e consorciados com caupi e sorgo granífero. Revista Ciência Agronômica, Fortaleza, v. 37, n. 2, p. 200-207, 2006.

DELOUCHE, J. C. Seed deterioration. Seed World, Chicago, v. 9, n. 4, p. 14-15, 1963.

EMPRESA BRASILEIRA DE PESQUISA AGROPECUÁRIA - EMBRAPA. Centro Nacional de Pesquisa de Solos (Rio de Janeiro, RJ). Sistema brasileiro de classificação de solos. Brasília: EmbrapaSPI, Embrapa-CNPS, 1999. 412 p.

FREITAS, R. Testes para avaliação da qualidade de sementes de algodoeiro e suas relações com o potencial de armazenamento e emergência das plântulas em campo. 1999. Dissertação (Mestrado em Fitotecnia) -Departamento de Fitotecnia. Universidade Federal de Viçosa, Viçosa.

GONÇALVES, N. P.; BENDEZÚ, J. M.; LIMA, C. A. S. Colheita e armazenamento da mamona. Informe Agropecuário, Belo Horizonte, v. 82, n. 7, p. 44-45, 1981.

HARRINGTON, J. F. Seed storage and longevity. In: KOZLOWSKI, T. T. (Ed.). Seed biology. New York: Academic Press, 1972. v. 3, p. 145-245.

LAGO, A. A.; ZINK, E.; RAZERA, L. F.; BANZATTO, N. V.; SAVY FILHO, A. Dormência em sementes de três cultivares de mamona. Bragantia, Campinas, v. 38, p. 41-44, 1979.

LINS, E. C.; TÁVORA, F. J. A. F.; ALVES, J. F. Efeito da ordem do racemo nas características de sementes de mamona (Ricinus communis L.).Ciência Agronômica, Fortaleza, v. 6, n. 1/2, p. 91-98, 1976.

LUCENA, A. M. A.; SEVERINO, L. S.; FREIRE, M. A. O.; COSTA, F. X.; BELTRÃO, N. E. M. Umidade e peso seco da semente e do fruto de mamona BRS Paraguaçu colhidos em três estádios de maturação. In: CONGRESSO BRASILEIRO DE MAMONA, 2., 2006. Campina Grande. Anais... Campina Grande: Embrapa Algodão, 2006. 1 CD- ROM.
MARCOS FILHO, J. Teste de envelhecimento acelerado. In: KRZYZANOWSKY, F. C.; VIEIRA. R. D.; FRANÇA NETO, J. B. Vigor de sementes: conceitos e testes. Londrina: ABRATES, Comitê de Vigor de Sementes, 1999. p. 321-324.

Fisiologia de sementes de plantas cultivadas. Piracicaba: USP, ESALQ, FEALQ, 2005. 495 p.

PINTO, L. C. G. Instrução normativa $n .^{\circ} 25$, de 16 de dezembro de 2005. Padrões de Sementes e de Campo. Ministério da Agricultura, Pecuária e do Abastecimento Gabinete do Ministro Anexo VII - Mamona. 2005. Disponível em: http://www.apassul.com.br/arquivo/ in25_novos_padroes/anexo7-mamona.pdf>. Acesso em: 20 abr. 2007.

SANTOS, V. L. M. Avaliação da germinação e do vigor de sementes de genótipos de soja (Glycine max (L.) Merrill), submetidas a estresses salino e osmótico. 1994. Tese (Doutorado em Fitotecnia) - Departamento de Fitotecnia. Universidade Federal de Viçosa, Viçosa.

SILVA, O. R. R. F.; CARVALHO, O. S.; SILVA, L. C. Colheita e descascamento. In: AZEVEDO, D. M. P.; LIMA, E. F. (Ed.). O Agronegócio da mamona no Brasil. EMBRAPA Algodão: Campina Grande, EMBRAPA, 2001. p. 337-350.

SOUZA, S. A.; CAVARIANI, C.; NAKAGAWA, J.; MARTINS, C. C. Accelerated aging test in castor seeds (Ricinus communis L.). In: INTERNATIONAL SEED CONGRESS, 28., 2007, Foz do Iguaçu. Resumos... Foz do Iguaçu, 2007. p. 112.

VANZOLINI, S.; ARAKI, C. A. S.; SILVA, A. C. T. M.; NAKAGAWA, J. Teste de comprimento de plântula na avaliação da qualidade fisiológica de sementes de soja. Revista Brasileira de Sementes, Pelotas, v. 29, n. 2, p. 90-96, 2007.

VIEIRA, A. R.; FRAGA, A. C.; VIEIRA, M. G. G. C.; OLIVEIRA, A. A. S.; ALMIR, J. Dormência e qualidade fisiológica de sementes de arroz armazenadas em diferentes regiões do Estado de Minas Gerais. Ciência e Agrotecnologia, Lavras, v. 26, n. 1, p. 33-44, 2002.

VIEIRA, D. V.; CARVALHO, N. M. Testes de vigor em sementes. Jaboticabal: FUNEP, 1994. 164 p. 